21 Thompson JS, Bragg LE, West WW. Serum enzyme levels during intestinal ischemia. Ann Surg 1990;211:369-73.

22 Marston A. Vascular disease of the gut. London: Arnold, 1986.

23 Bvnum TE. Hanley HG. Effects of digitalis on estimated splanchnic blood flow. $\mathcal{F}$ Lab Clin Med 1982:99:84-9

24 Fink MP. Systemic and splanchnic hemodynamic derangements in the sepsis syndrome. In: Marston A, Bulkley GB, Green RGF, Hagland U, eds. Splanchnic ischemia and multiple organ failure. London: Arnold, 1990:101-6.

25 Taylor KM. Vasopressor release and multiple organ failure in cardiac surgery. In: Marston A Bulkley GB, Green RGF, Hagland U, eds. Splanchnic ischemia and multiple organ failure. London: Arnold, 1990:88-99.
26 Carey CS, Okada F, Monson DO, Yao ST, Shoemaker WC. Intestinal infarction in shock with survival after resection. FAMA 1974;229:1451-3.

Bergqvist D, Bowald S, Eriksson I, Lannerstad O, Takolander R. Small intestinal necrosis after aorto-iliac reconstruction. Br F Surg 1986; 73:28-30.

Ingoldby $\mathrm{CJH}$. The value of polymyxin $\mathrm{B}$ in endotoxaemia due to experimental obstructive jaundice and mesenteric ischaemia. Br 7 Surg 1980;67:565-7.

29 Schonberg MH, Muhl E, Sellin D, Younes M, Schildberg FW, Haglund U. Posthypertensive generation of superoxide free radicals - possible role in the pathogenesis of the intestinal mucosa generation of superoxide free radicals- possit

30 Granger DN, Rutili G, McCord JM. Superoxide radicals in feline intestinal ischemia. Gastro enterology 1981;81:22-9.

\title{
Vitamin A, liver consumption, and risk of birth defects
}

\author{
Liver is a cheap source of many nutrients
}

An excessive intake of vitamin A immediately before or during pregnancy substantially increases the risk of birth defects. ${ }^{\prime}$ The Teratology Society has therefore recommended that vitamin A supplementation (as retinol or retinyl esters) should be limited to $8000 \mathrm{IU}(2400 \mu \mathrm{g})$ a day. ${ }^{2}$ The chief medical officer has reiterated this advice in even stronger terms by cautioning women who are, or who may become, pregnant "against taking any dietary supplements - including tablets and fish-liver oil drops-containing vitamin A, except on the advice of a doctor or antenatal clinic." ${ }^{3} \mathrm{He}$ goes on to say that as a matter of prudence such women should not eat liver and liver products because of their high retinol content. Is he being overcautious and sowing the seeds of yet another food scare?

A recent epidemiological study of birth defects diagnosable within the first three days of life showed that among 11293 non-chromosomal cases of birth defect and 11193 controls, 16 cases and 14 controls were exposed to vitamin $\mathrm{A}$ intakes over $10000 \mathrm{IU} /$ day (odds ratio $1 \cdot 1 ; 95 \%$ confidence interval 0.5 to $2 \cdot 5$ ). The use of vitamin $\mathrm{A}$ alone rather than multivitamin supplements conferred a much higher risk $(9.9 ; 1.4$ to $430 \cdot 1)$, probably because of the higher doses received (63636 IU $v 20263$ IU). When a dose-response relation was examined intakes over 40000 IU were associated with an odds ratio of $2.7(0.8$ to 11.7$)$, and the risk of birth defects was highest when supplements were taken in the first two months of pregnancy. None of the mothers had a clear medical reason for taking vitamin A supplements. The authors concluded that exposures below about $10000 \mathrm{IU} /$ day were unlikely to be teratogenic.

Typical dietary intakes of retinol from food sources among women of childbearing age in Britain were recently reported to be about 1400 IU/day. ${ }^{5}$ The 97.5 centile was around $20000 \mathrm{IU} /$ day over the one week survey. This does not imply that $2 \cdot 5 \%$ of women were consuming more than $20000 \mathrm{IU} /$ day week in, week out but rather that in the week of the survey they consumed high amounts; their average intake, measured over several weeks, would probably have been substantially less. There is no evidence, therefore, that most women are in danger of exceeding an average intake of $10000 \mathrm{IU} /$ day.

The average retinol content of liver has increased over the past decade to reach values typically between $66000 \mathrm{IU}$ and $130000 \mathrm{IU} / 100 \mathrm{~g}$. These high levels might be of concern for women who regularly eat more than $100 \mathrm{~g}$ of liver a week, but there is only one reported case of birth defects in a child born to a woman who ate large amounts of liver daily. Given that the placental barrier to vitamin $\mathrm{A}$ is incomplete between the fourth and tenth weeks of gestation, ${ }^{6}$ there might be concern about a bolus effect, but there has been only one reported case to substantiate that concern: a woman who accidentally ingested $500000 \mathrm{IU}$ in the second month of pregnancy gave birth to an infant with multiple birth defects. ${ }^{7}$ All other reports of birth defects have been associated with a daily consumption of $25000 \mathrm{IU}$ or more over several weeks or months. ${ }^{1}$ The recommendation that a large segment of the population should exclude liver entirely could thus be seen as an overinterpretation of very limited evidence.

It is important to remember the other end of the nutritional spectrum: those women whose diets may be lacking in nutrients. Doyle and colleagues reported that among women on low incomes low birth weight was significantly associated with poor intakes of thiamin, riboflavin, niacin, zinc and iron, ${ }^{8}$ all of which (together with other nutrients such as folate and vitamin B-12) liver provides in generous amounts at low cost. ${ }^{9}$ Fetal nutritional insufficiency, low birth weight, and the associated risk of defects is thus likely to be a far greater problem on a population basis than the risk of defect associated with vitamin A toxicity.

Most women do not need to take vitamin A supplements either before or during pregnancy, and those who do should be under medical supervision. There is justifiable concern about the excessive concentrations of vitamin $\mathrm{A}$ in liver, but it is equally important to remember that liver is a source of many nutrients and a desirable adjunct to the diets of many women, particularly those on low incomes. It might therefore be sensible to be less alarmist and to advise women who are pregnant or who may become pregnant not to consume more than $50 \mathrm{~g}$ of liver a week until the amount of vitamin $\mathrm{A}$ in liver is reduced through appropriate action by the meat producers. Consumption of liver sausage or paté, in which the liver is diluted by the inclusion of other ingredients, should similarly be limited to about $100 \mathrm{~g}$ a week.

MICHAEL NELSON

Lecturer in Nutrition,

King's College London,

London W87AH

\footnotetext{
1 Rosa FW, Wilk AL, Kelsey FO. Teratogen update: vitamin A congeners. Teratology 1986;33: $355-64$.

Teratology Society. Recommendations for vitamin A use during pregnancy. Teratology 1987;35: 269-75.

Department of Health. Women cautioned: watch your vitamin A intake. London: Department of Health, 1990. (18 October.)

Martinez-Frias ML, Salvador J. Epidemiological aspects of prenatal exposure to high doses of vitamin A in Spain. Eur F Epidemiol 1990;6:118-23.

Gregory $\mathrm{J}$, Foster $\mathrm{K}$, Tyler $\mathrm{H}$, Wiseman $M$. The dietary and nutritional survey of British adults. London: $\mathrm{HMSO}, 1990$.

6 Wallingford JC, Underwood BA. Vjtamin A deficiency in pregnancy, lactation, and the nursing child. In: Bauerfiend JC, ed. Vitamin A deficiency and its control. London: Academic Press, 1986. child. In: Bauerfiend J ed. Vitamin A deficiency and tis control. London: Academic Press, 1986. Mounoud $\mathrm{RL}$, Klein $\mathrm{D}$, Weber $\mathrm{F}$. A propos d'un cas de syndrome de Goldenhar:
la vitamine A chez la mère pendant la grossesse. F Genet Hum 1975;28:135-54. la vitamine A chez la mère pendant la grossesse. $\mathcal{F}$ Genet Hum 1975;28:135-54.
Doyle W, Crawford MA, Wynn AHA, Wynn SW. Maternal nutrient intake and birth-weight. 8 Doyle W, Crawford MA, Wynn AHA, Wynn SW. Ma

foumal of Human Nutrition and Dietetics 1989;2:415-22.
9 Paul AA, Southgate DAT. McCance and Widdowson's the composition of foods. 4th ed. London: HMSO, 1978
} 